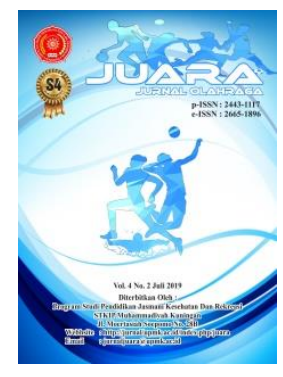

\title{
Strike and Fielding Games pada Keterampilan Gerak dasar
}

\section{Strike and Fielding Games on Fundamental Movement Skills}

Vicki Ahmad Karisman', Gita Febria Friskawati

1,2 Department of Physical Education, Health and Recreation, STKIP Pasundan, Jl. Permana No.32 B, Citeureup, Kec. Cimahi Utara, Kota Cimahi, Jawa Barat 40512, Indonesia

Email: vicky4kharisman@gmail.com ${ }^{1}$, gita032@gmail.com ${ }^{2}$

\begin{tabular}{l} 
Info Artikel \\
\hline Sejarah Artikel: \\
Diterima 18 September 2019 \\
Disetujui 04 Januari 2019 \\
Dipublikasikan 08 Januari \\
2019
\end{tabular}

Keywords:

Fundamental motor skills, Physical education, Striking and Fielding games

\begin{abstract}
Abstrak
Keterampilan gerak dasar penting dimiliki anak untuk dapat memperagakan keterampilan kecabangan olahraga pada masa ini dan masa yang akan datang. Tujuan penelitian untuk mengeksplorasi kontribusi dari strike and fielding games pada keterampilan gerak dasar. Partisipan dalam penelitian ini adalah siswa kelas empat sebanyak 34 orang, teknik pengambilan sampel menggunkan total sampling. Metode penelitian yang digunakan adalah eksperimen dengan desain pretest and posttest group desain. Perlakuan dilakukan selama dua bulan dengan 16 kali pertemuan masing masing selama 2 jam. Instrumen yang digunakan untuk mengukur keterampilan gerak dasar adalah the Test Gross Motor Development (TGMD) edisi ke-2. Yang terbagi kedalam dua jenis tes yaitu tes lokomotor dan object skill. Selanjutnya uji paired sample test menunjukan 0,000 $<0,05$ berarti bahwa terdapat peningkatan yang berarti dari keterampilan gerak dasar yang di intervensi oleh strike and fielding games. Penelitian ini menunjukan bahwa melalui permainan strike end fielding games siswa mengalami perkembangan dari sisi keterampilan gerak dasar. Dengan perkembangan gerak dasar yang baik diharapkan siswa dapat berpartisipasi aktif dalam aktivitas fisik pada masa yang akan datang. kesimpulan dari penelitian ini adalah terdapat pengaruh yang berarti dari strike and fielding games terhadap keterampilan gerak dasar siswa sekolah dasar.
\end{abstract}

\footnotetext{
Abstract

To be skillful in every sport performance, every child is urged to possess the fundamental motor skills. This study aims to explore the contribution and the use of striking and fielding games in elementary school in an attempt of improving students fundamental motor skills. The researcher utilized an experimental method with pretest and posttest group design. This study invited 34 students of 4th grader as the research sample which was selected by implementing total sampling technique. The treatment was given for 16 meetings. For the instruments, the researcher used the 2nd edition of Test Gross Motor Development (TGMD); which was divided into
} 
two kinds of test; those are locomotor and object skill test. Based on the data analysis by using paired sample test, it showed that the significant score of pretest and posttest $0.000<0.05$. It means that there was a significant improvement of the students' fundamental motor skills that are intervened by striking and fielding games. This study also indicated that through these games, the students experienced the advancement in their fundamental motor skills. By this advancement, the students are expected to be able to participate actively in their physical activities. In conclusion, this study revealed the significant improvement of the striking and fielding games on the students' fundamental motor skills.

(C) 2020 Vicki Ahmad Karisman, Gita Febria Friskawati

Under the license CC BY-SA 4.0

\footnotetext{
Alamat korespondensi: J1. Permana No.32 B, Citeureup, Kec. Cimahi Utara, Kota Cimahi, Jawa Barat

E-mail : : vicky4kharisman@gmail.com

No Handphone : 081214511454
}

\section{PENDAHULUAN}

Keterampilan gerak dasar didefinisikan sebagai pola dasar belajar yang tidak terjadi secara alami dan disarankan untuk menjadi dasar bagi aktivitas fisik dan olahraga yang lebih kompleks. Mereka dapat diklasifikasikan ke dalam tiga kategori berbeda: locomotor (melibatkan pergerakan tubuh misalnya, berlari), object control (keterampilan manipulatif misalnya, menangkap bola) dan keterampilan stabilitas seperti menyeimbangkan (Gallahue, Ozmun, \& Goodway, 2012). (Goodway et al., 2012) mengungkapkan bahwa anak-anak yang lebih aktif secara fisik mengembangkan ketrampilan gerak dasar dan selanjutnya akan berdampak pada persepsi yang baik pada kompetensi anak-anak.

Keterampilan gerak dasar akan berkontribusi pada pemeliharaan badan yang sehat. Keterampilan gerak dasar adalah blok bangunan dari gerakan yang lebih maju, kompleks yang diperlukan untuk berpartisipasi dalam permainan, olahraga atau aktivitas fisik spesifik konteks lainnya (Samuel W. Logan et al., 2018). Temuan menunjukkan rendahnya keterampilan gerak dasar di antara anak-anak sekolah dasar Irlandia. Hal ini diakibatkan oleh rendahnya program aktifitas fisik pada

anak (Behan, Belton, Peers, O'Connor, \& Issartel, 2019).

Keterampilan gerak dasar merupakan hal yang penting dalam masa pertumbuhan dan perkembangan anak. Penguasaan keterampilan gerak dasar yang baik dapat memberikan manfaat yang besar terutama dalam melakukan berbagai aktivitas fisik. Seseorang yang meiliki waktu yang lebih banyak untuk melakukan latihan pada rentang usia 2 tahun hingga 7 tahun secara berkelanjutan dapat meningkatan keterampilan motoric dasar. Selama masa remaja dan dewasa, ini adalah landasan untuk sukses dalam keterampilan olahraga (Senturk et al., 2015). Penelitian menunjukan kemampuan motorik kelas IV SD dapat dikategorikan sedang. Persentase klasifikasi kriteria kemampuan motorik siswa yaitu kategori baik sekali 5.04\%, kategori baik $24,37 \%$, kategori sedang 39,50\%, kategori kurang 24,37\%, dan kategori kurang sekali 6,72\% (Wicaksono \& Nurhayati, 2013). Hal ini menunjukan perlunya perlakuan yang tepat dalam meningkatkan keterampilan gerak dasar.

Keterampilan gerak dasar tidak akan didapatkan begitu saja, namun melalui berbagai program. Pola pergerakan dasar ini tidak diperoleh secara alami selama proses pematangan (Hardy et al., 2010). Oleh sebab itu, guru perlu menyusun dan melaksanakan 
kegiatan yang sesuai dengan perkembangan, dalam pembelajaran penjas akan menjadi peluang untuk mengmbangakn keterampilan yang diinginkan. (S. W. Logan et al., 2012). Studi sebelumnya tentang aktivitas pada istirahat sekolah, atau di kelas pendidikan jasmani, tentang keterampilan motorik, menunjukan bahwa terjadi peningkatan yang positif pada keterampilan gerak dasar pada anak (Morgan et al., 2013).

Penelitian di masa depan harus berusaha untuk mengeksplorasi tingkat aktivitas fisik anak-anak. Bersamaan dengan itu pengembangan kebugaran dan pemahaman kepada anak untuk dapat berpartisipasi dalam aktivitas fisik (Behan et al., 2019). Selain itu (Cohen et al., 2014) menyimpulkan bahwa keterampilan gerak dasar tidak berdampak pada angka aktifitas fisik dan kebugaran kardiorespirasi anak. Namun demikian dalam penelitian ini intervensi yang diberikan melalui permainan diharapakan dapat berdampak pada keterampilan gerak dasar.

Keterampilan gerak dasar dapat diajarkan dan dipraktekkan dalam lingkungan seperti permainan, di mana permainan, baik terstruktur atau tidak terstruktur diintegrasikan ke dalam kurikulum atau praktik lingkungan. (W.Piltz, 2013) dalam Model Praktek Bermain anak menunjukkan keahlian dalam keterampilan dapat diajarkan dalam konteks permainan. Guru yang menunjukkan pemahaman mendalam tentang pedagogi yang berpusat pada permainan mampu menyeimbangkan pengajaran keterampilan / taktik dalam konteks permainan (Dudley \& Baxter, 2013). Selain itu dalam konteks pendidikan jasmani, permainan apa pun merupakan pengalaman yang baik untuk menumbuhkan refleksi pada tindakan belajar tentang tindakan pemain, yaitu, untuk menumbuhkan refleksi proaktif, sebagai pembelajaran yang bermakna untuk guru pendidikan jasmani masa depan (Lavega et al., 2018).
Salah satu permainan yang dapat dilakukan adalah melalui striking and fileding games. Striking and Fielding Games adalah kegiatan di mana pemain mencetak poin dengan memukul objek dan berlari ke area bermain yang ditentukan atau mencegah lawan mencetak poin dengan mengambil objek dan mengembalikannya untuk menghentikan permainan. Tujuan utama dari Games Concept Approach (GCA) adalah untuk meningkatkan kinerja permainan siswa. Pendekatan ini bertujuan untuk meningkatkan minat dan kesenangan yang lebih besar, keterampilan pemecahan masalah dan pengambilan keputusan yang lebih baik, dan peningkatan kompetensi siswa dalam belajar dan bermain permainan (Tan et al., 2002). Selain itu (Michael W. Metzler, 2011) menyatakan bahwa "model seperti permainan taktis dan pendidikan olahraga mengandung berbagai elemen yang melekat dalam praktik terbaik, menjadikannya ideal untuk mempromosikan pengetahuan konten pedagogis". Melalui permainan, peserta akan mempelajari keterampilan dan taktik utama untuk permainan.

Permainan ini pada dasarnya mengandung berbagai keterampilan gerak dasar, baik locomotor seperti gerakan berjalan, berlari, melompat, dan berguling, maupun object skill seperti memukul, melempar, menangkap bola. Di Indonesia permainan strike and filed games yang paling sering dimainkan adalah kasti, rounders, slag ball dan kippers, yang pada dasarnya memiliki peluang dalam mengembangkan keterampilan gerak dasar.

\section{METODE}

Penelitian ini menggunakan metode eksperimen dengan pretes and posttest group design (Fraenkel, Wallen, \& Hyun, 2012). Populasi penelitian ini adalah siswa Sekolah 
Dasar kelas IV sebanyak 34 siswa, dengan teknik pengambilan sampel menggunakan total sampling. Penelitian ini dilakukan sebanyak 16 kali pertemuan dengan empat Striking and Fielding Games yaitu Kasti, Kippers, Rounders, dan Slag ball. Adapun instrument yang digunakan adalah Test of Gross Motor Development (TGMD) $2^{\text {nd }}$ Edition (Ulrick, 2000). Enam jenis tes locomotor yaitu run, gallop, hop, leap, horizontal jump dan slide. Dan enam jenis tes object skill yaitu striking a stationary ball, stationary dribble, catch, kick, overhand throw, dan underhand roll. Analisis dan pengolahan data menggunakan SPPS 21 dengan paired sample t-test.

\section{HASIL DAN PEMBAHASAN}

\section{Hasil}

Berdasarkan hasi analisis dan pengolahan data diperoleh hasil, uji normalitas menunjukan Hasil perhitungan uji normalitas menunjukan hasil normalitas pretest 0,068 dan $0,353>0,05$ dan hasil normalitas posttest menunjukan distribusi normal.

Tabel 1 Uji Normalitas

\begin{tabular}{llll}
\hline \multicolumn{3}{l}{ One-Sample Kolmogorov-Smirnov Test } \\
\hline $\mathrm{N}$ & & pretest & posttest \\
Normal & Mean & 34 & 34 \\
Parameters & Stb & 5.1176 & 7.4706 \\
& Deviation & 1.17460 & 1.33110 \\
Most Extreme & Absolute & .241 & .159 \\
Differences & Positive & .241 & .159 \\
Kolmogorov- & Negative & -.171 & -.155 \\
$\begin{array}{l}\text { Smirnov Z } \\
\text { Asymp. Sig. }\end{array}$ & & 1.406 & .930 \\
(2-tailed) & & .068 & .353 \\
\hline
\end{tabular}

a. Test distribution is Normal.

b. Calculated from data.

Nilai hasil uji Paired Samples Test ada data hasil pre tes dan post test keterampilan gerak dasar menunjukan nilai signifikansi sebesar 0,000. Karena signifikansi pada data pre test dan post test keterampilan motorik dasar $<0.05$, maka dapat disimpulkan bahwa terdapat pengaruh yang signifikan dari striking and fileding games terhadap keterampilan gerak dasar siswa sekolah dasar.

Tabel 2 Hasil Uji Paired Samples Test

\begin{tabular}{|c|c|c|c|c|c|c|c|c|c|}
\hline \multicolumn{10}{|c|}{ Paired Samples Test } \\
\hline & & \multicolumn{5}{|c|}{ Paired Differences } & \multirow[b]{3}{*}{$\mathrm{t}$} & \multirow[b]{3}{*}{ df } & \multirow{3}{*}{$\begin{array}{l}\text { Sig. }(2- \\
\text { tailed })\end{array}$} \\
\hline & & \multirow[b]{2}{*}{ Mean } & \multirow{2}{*}{$\begin{array}{c}\text { Std. } \\
\text { Deviation }\end{array}$} & \multirow{2}{*}{$\begin{array}{l}\text { Std. Error } \\
\text { Mean }\end{array}$} & \multicolumn{2}{|c|}{$\begin{array}{l}95 \% \text { Confidence Interval of } \\
\text { the Difference }\end{array}$} & & & \\
\hline & & & & & Lower & Upper & & & \\
\hline Pair & pretest - & - & 1.53509 & .26327 & -2.88856 & -1.81732 & & 33 & .000 \\
\hline 1 & posttest & 2.35294 & & & & & 8.93 & & \\
\hline
\end{tabular}

Tabel hasil uji Paired Samples Test menunjukan bahwa, terjadi peningkatan dari jumlah rata-rata keteremapilan gerak dasar pada rata-rata nilai pretest 5,12 dan pada rata-rata 
posttest sebesar 7,47. Hal ini menunjukan keterampilan gerak dasar pada siswa.

bahwa telah terjadi peningkatan rata-rata

Grafik 1 Rata-rata Ketreampilan Gerak Dasar

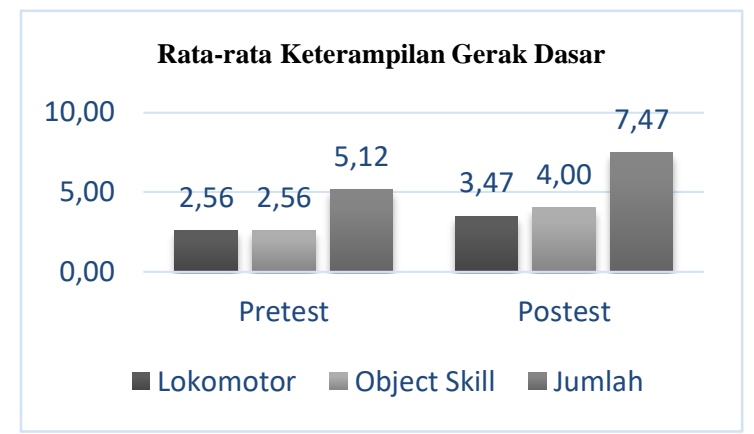

\section{Pembahasan}

Penelitian yang telah dilakukan berjalan sesuai dengan yang diharapkan oleh peneliti, hal ini dapat terlihat dari hasil penelitian dan terjadi peningkatan yang signifikan. Keterampilan akan membantu siswa menjadi percaya diri terhadap berbagai keterampilan kecabangan olahraga. Menggunakan permainan yang menyenangkan untuk mengajar keterampilan gerak dasar akan membuat proses lebih menarik dan siswa akan lebih cenderung mengembangkan sikap positif terhadap aktivitas fisik. Ini adalah langkah penting menuju kehidupan yang sehat dan aktif (Mandigo, Francis, \& Lodewyk, 2007).

Permainan strike and fielding games (kasti) memberikan kontribusi yang unggul pada komponen kecepatan lari, kemudian diikuti oleh kelincahan, koordinasi mata dan tangan, dan keseimbangan. Hal ini karena memang permainan bola kasti mempunyai karakteristik yang dapat mendukung pengembangan kecepatan lari, kelincahan, keseimbangan, serta koordinasi mata dan tangan (Pulung, 2014). Selain itu berbagai teknik dalam permainan kasti, rounders, slag ball dan kippers seperti berjalan, berlari, melopat, melempar, menangkap, dan memukul bola menjadikan siswa memiliki keterampilan gerak dasar yang baik serta meningkat secara signifikan. Selain itu (Byl \& Kloet, 2014) Bermain memungkinkan anak-anak untuk menggunakan kreativitas mereka sambil mengembangkan imajinasi mereka, ketangkasan, dan kekuatan fisik, kognitif, dan emosional. Bermain itu penting untuk perkembangan otak yang sehat.

Striking and Fielding Games memiliki karakteristik kecepatan yang lebih lambat dibandingkan dengan game invasi dan net / wall, yang mengurangi tingkat kerumitan taktis di dalamnya. Sifat permainan yang lebih lambat memberikan siswa lebih banyak waktu untuk membuat keputusan dalam permainan (Fisette \& Mitchell, 2010). Siswa memiliki banyak waktu untuk mempelajari berbagai teknik melalui berbagai permainan yang dapat meningkatkan keterampilan gerak dasar.

Kemudian dalam Striking and Fielding Games, pemain lapangan yang memukul bola berusaha menjauhkan bola, berlari serta menghindari lawan sampai mencetak poin. Keterampilan dalam menjaga pertahan seperti menangkap bola, melempar, untuk mendapatkan giliran bermain sebagai pemain lapangan (The Physical Educator.com, 2017). Keterampilan gerak dasar ini berkembang seiring dengan berjalannya permainan. Selanjutnya bahwa, keterampilan motorik diajarkan bersama dalam koteks permainan, menunjukan bahwa keterampilan gerak dasar berkontribusi terhadap pengembangan dan menyediakan kerangka kerja untuk instruksi dalam model pembelajaran terpadu (Barnett et al., 2016). Dengan demikian pembelajaran yang dilakukan melalui berbagai permainan 
khususnya striking and fielding games khususnya dalam penelitian ini adalah permainan kasti, kippers, slag ball dan rounders memberikan pengaruh yang signifikan terhadap keterampilan gerak dasar.

Dalam penelitian ini menunjukan bahwa melalui intervensi yang dilakukan dapat meningkatkan keterapilan gerak dasar. Penelitian selanjutnya hendakanya mengembangkan permainan-permainan ini yang disesuaikan dengan perkembangan jaman. Selain itu pula penelitian selanjutnya diharapkan dapat menggunkan kelompok control dalam penelitiannya. Karena dalam penelitian ini terbatas hanya pada kelompok eksperimennya saja.

\section{SIMPULAN}

Tujuan penelitian ini adalah untuk mengetahui pengaruh dari strike and fielding games terhadap keterampilan gerak dasar siswa. Analisis dan pengolahan data menunjukan adanya perubahan yang signifikan dari strike and fielding games terhadap keterampilan gerak dasar. Ini menunjukan bahwa intervensi penelitian melalui berbagai permainan seperti kasti, kippers, slag ball dan rounders bisa dijadikan alternative dalam mengembangkan keterampilan gerak dasar.

\section{UCAPAN TERIMA KASIH}

Ucapan terimakasih penulis sampaikan kepada semua pihak yang telah membantu terlaksananya penelitian ini. Kepada para partisipan, team pengajar dan peneliti sejawat.

\section{DAFTAR PUSTAKA}

Barnett, L. M., Stodden, D., Cohen, K. E., Smith, J. J., Lubans, D. R., Lenoir, M., ... Morgan, P. J. (2016). Fundamental Movement Skills: An Important Focus. Journal of Teaching in Physical Education, 35(3), 219-225. https://doi.org/10.1123/jtpe.2014-0209
Behan, S., Belton, S., Peers, C., O'Connor, N. E., \& Issartel, J. (2019). Moving WellBeing Well: Investigating the maturation of fundamental movement skill proficiency across sex in Irish children aged five to twelve. Journal of Sports Sciences, $\quad 37(22), \quad 2604-2612$. https://doi.org/10.1080/02640414.2019.1 651144

Byl, J., \& Kloet, B. V. (2014). Physical education for homeschool, classroom, and recreation settings : 102 games with variations. United States of America: Human Kinetics.

Cohen, K. E., Morgan, P. J., Plotnikoff, R. C., Callister, R., \& Lubans, D. R. (2014). Fundamental movement skills and physical activity among children living in low-income communities: A crosssectional study. International Journal of Behavioral Nutrition and Physical Activity, $\quad 11(1), \quad 1-9$. https://doi.org/10.1186/1479-5868-11-49

Dudley, D., \& Baxter, D. (2013). Metacognitive analysis of pre-service teacher conception of Teaching Games for Understanding (TGfU) using blogs. Asia-Pacific Journal of Teacher Education, $\quad 41(2), \quad 186-196$. https://doi.org/10.1080/1359866X.2013. 777028

Fisette, J. L., \& Mitchell, S. (2010). Frameworks for Diagnosing Student Performance Problems in Striking/Fielding and Target Games. JOPERD: The Journal of Physical Education, Recreation \& Dance, 81(8), 43-56. https://doi.org/10.1080/07303084.2010.1 0598528

Fraenkel, J. R., Wallen, N. E., \& Hyun, H. H. (2012). How to Design and Evaluate Research in Education. In The McGrawHill Companies. https://doi.org/10.1017/CBO9781107415 324.004

Gallahue, D. L., Ozmun, J. C., \& Goodway, J. 
D. (2012). Understanding motor development: Infants, children, adolescents, adults (7th ed.). McGrawHill.

Goodway, J. D., Garcia, C., Roberton, M. A., Langendorfer, S. J., Stodden, D. F., Garcia, L. E., \& Rudisill, M. E. (2012). A Developmental Perspective on the Role of Motor Skill Competence in Physical Activity: An Emergent Relationship. Quest, 60(2), 290-306. https://doi.org/10.1080/00336297.2008.1 0483582

Hardy, L. L., King, L., Farrell, L., Macniven, R., \& Howlett, S. (2010). Fundamental movement skills among Australian preschool children. Journal of Science and Medicine in Sport, 13(5), 503-508. https://doi.org/10.1016/j.jsams.2009.05.0 10

Lavega, P., Prat, Q., De Ocáriz, U. S., Serna, J., \& Muñoz-Arroyave, V. (2018). Reflection-on-action learning through traditional games. The case of la pelota sentada (sitting ball) | Aprendizaje basado en la reflexión sobre la acción a través de los juegos tradicionales. El caso de la pelota sentada. Cultura y Educacion, 30(1), 142-176. https://doi.org/10.1080/11356405.2017.1 421302

Logan, S. W., Robinson, L. E., Wilson, A. E., \& Lucas, W. A. (2012). Getting the fundamentals of movement: A metaanalysis of the effectiveness of motor skill interventions in children. Child: Care, Health and Development, 38(3), 305-315. https://doi.org/10.1111/j.13652214.2011.01307.x

Logan, Samuel W., Ross, S. M., Chee, K., Stodden, D. F., \& Robinson, L. E. (2018). Fundamental motor skills: A systematic review of terminology. Journal of Sports Sciences, 36(7), 781796.

https://doi.org/10.1080/02640414.2017.1 340660
Mandigo, J., Francis, N., \& Lodewyk, K. (2007). Physical Literacy Concept Paper Ages 0-12 Years. Retrieved from http://physicalliteracy.ca/wpcontent/uploads/2016/08/Physical_Litera cy_Concept_Paper.pdf

Michael W. Metzler. (2011). Instructional Models for Physical Education. Holcomb Hathaway, Incorporated.

Morgan, P. J., Barnett, L. M., Cliff, D. P., Okely, A. D., Scott, H. A., Cohen, K. E., \& Lubans, D. R. (2013). Fundamental Movement Skill Interventions in Youth: A Systematic Review and Meta-analysis. Pediatrics, 132(5), e1361-e1383. https://doi.org/10.1542/peds.2013-1167

Pulung, R. (2014). Pengaruh Permainan Bola Kasti Terhadap Peningkatan Kemampuan Gerak Umum (General Motor Ability). Jurnal Sport Area, 5363.

Senturk, U., Beyleroglu, M., Guven, F., Yilmaz, A., \& Akdeniz, H. (2015). Motor skills in pre-school education and affects to 5 year old children's psychomotor development. Turkish Journal of Sport and Exercise, 17(2), 42. https://doi.org/10.15314/tjse.38665

Tan, S., Wright, S., Mcneill, M., Fry, J., \& Tan, C. (2002). Implementating the Games Concept Approach in Singapore Schools: A Preliminary Report. React, 21(1), 77-84.

The Physical Educator.com. (2017). Striking and Fielding Games. Retrieved from https://thephysicaleducator.com/game_c ategory/strikingfielding/

Ulrick, D. A. (2000). Test of Gross Motor Development 2.

W.Piltz, A. L. \&. (2013). Play Practice-2nd Edition (2nd ed.). Human Kinetics.

Wicaksono, D. C., \& Nurhayati, F. (2013). Survey Kemampuan Motorik Siswa 
Vicki Ahmad Karisman ${ }^{1}$, Gita Febria Friskawati ${ }^{2}$ JUARA : Jurnal Olahraga 5 (2) (2020)

Sekolah Dasar Muhammadiyah Kelas IV

Ajaran 2012 -2013.01, 98-103.

Se-Kecamatan Taman Sidoarjo Tahun 